\title{
SUMATRA TERCINTA. HET GELIEFDE EILAND ${ }^{1}$
}

Vanaf oktober presenteert Museum Volkenkunde in Leiden voor de eerste keer een tentoonstelling over het Indonesische eiland Sumatra. Rode draad van de tentoonstelling is het veelzijdige antwoord op de vraag wat uiteenlopende handelscontacten door de eeuwen heen voor het eiland en haar bewoners hebben betekend. En die invloed blijkt groot te zijn en soms onverwachte verhalen op te leveren.

Sumatra lag aan een van de belangrijkste handelsroutes, namelijk de maritieme route die China in het oosten verbond met India, het MiddenOosten en Europa in het westen. Deze strategische ligging aan de straat van Malakka als knooppunt van eeuwenoude handelsroutes heeft ervoor gezorgd dat er veel uitwisseling van goederen en ideeën is geweest. Dit wordt bijvoorbeeld duidelijk aan de hand van de architectuur, het geloof en de beeldende kunst.

De tentoonstelling, onderdeel van het samenwerkingsproject Museum Baru/ The New Museum, bevat naast voorwerpen van Museum Volkenkunde bruiklenen van het Museum Nasional in Jakarta en verschillende provinciale Sumatraanse musea. Enkele topstukken, zoals gouden attributen van sultans van Siak en Jambi, bewerkte krissen, Chinees lakwerk, bijzondere weefsels en belangrijke hindoe-boeddhistische beelden, zijn nog nooit in Nederland te zien geweest.

$\mathrm{Al}$ sinds het begin van de $20^{\mathrm{e}}$ eeuw in Nederland en ook zeer de moeite waard, zijn de schitterende voorwerpen van de collectie Veltman (collectie 1599), een collectie vooral verzameld in Aceh (Noord-Sumatra) aan het eind van de $19^{\mathrm{e}}$, begin van de $20^{\mathrm{e}}$ eeuw. Onder de tentoongestelde voorwerpen van Museum Volkenkunde zijn 25 stukken opgenomen uit deze collectie Veltman.

\section{Collectie Veltman}

Vanaf 1896 verbleef Theodorus Jacobus Veltman (1868-1943), kapitein van het Koninklijk Nederlands-Indische leger (ridder derde klasse in de Militaire Willems Orde) en bestuursambtenaar, in Aceh. ${ }^{2}$ Gestationeerd in Poelo Raya en Meulobah, was hij onder andere in 1905 betrokken bij de gevangenneming van Tjoek Nyak Dien, verzetsstrijdster tegen de Nederlanders. Veltman was ook zeer geïnteresseerd in de Acehse cultuur. Dit komt tot uiting in de omvang en veelzijdigheid van zijn kunstverzameling. Gedurende de 20 jaar die Veltman doorbracht in Nederlands-Indië verzamelde hij uiteenlopende soorten voorwerpen: wapens, sieraden, textiel, muziekinstrumenten, werktuigen en ook tekeningen. Ook verdiepte hij zich in de wetenschap en schreef hij bijvoorbeeld een artikel over de goud- en zilversmeedkunst in Aceh. ${ }^{3}$ Collectie 1599 bestaat uit 698 voonwerpen die begin $20^{\circ}$ eeuw in het bezit: 15 : 36PM kwamen van Museum Volkenkunde in Leiden, toen nog 's Rijks Ethnographisech ${ }^{\text {jas }}$ 


\section{Afbeelding 1}

Haarspelden, Aceh, voor 1907, I.9,5 cm., b. $2,7 \mathrm{~cm}$., Museum Volkenkunde, inv.nr 1599-52a; I. 9,8 cm., b. 2,7 cm., Museum Volkenkunde, inv.nr 1599-53b. Foto: Ben Grishaaver

\section{Afbeelding 2}

Een paar oorsieraden, Aceh, voor 1907, d. 3,2 cm., h I, cm., Museum Volkenkunde, inv.nr 1599-55. Foto: Ben Grishaaver
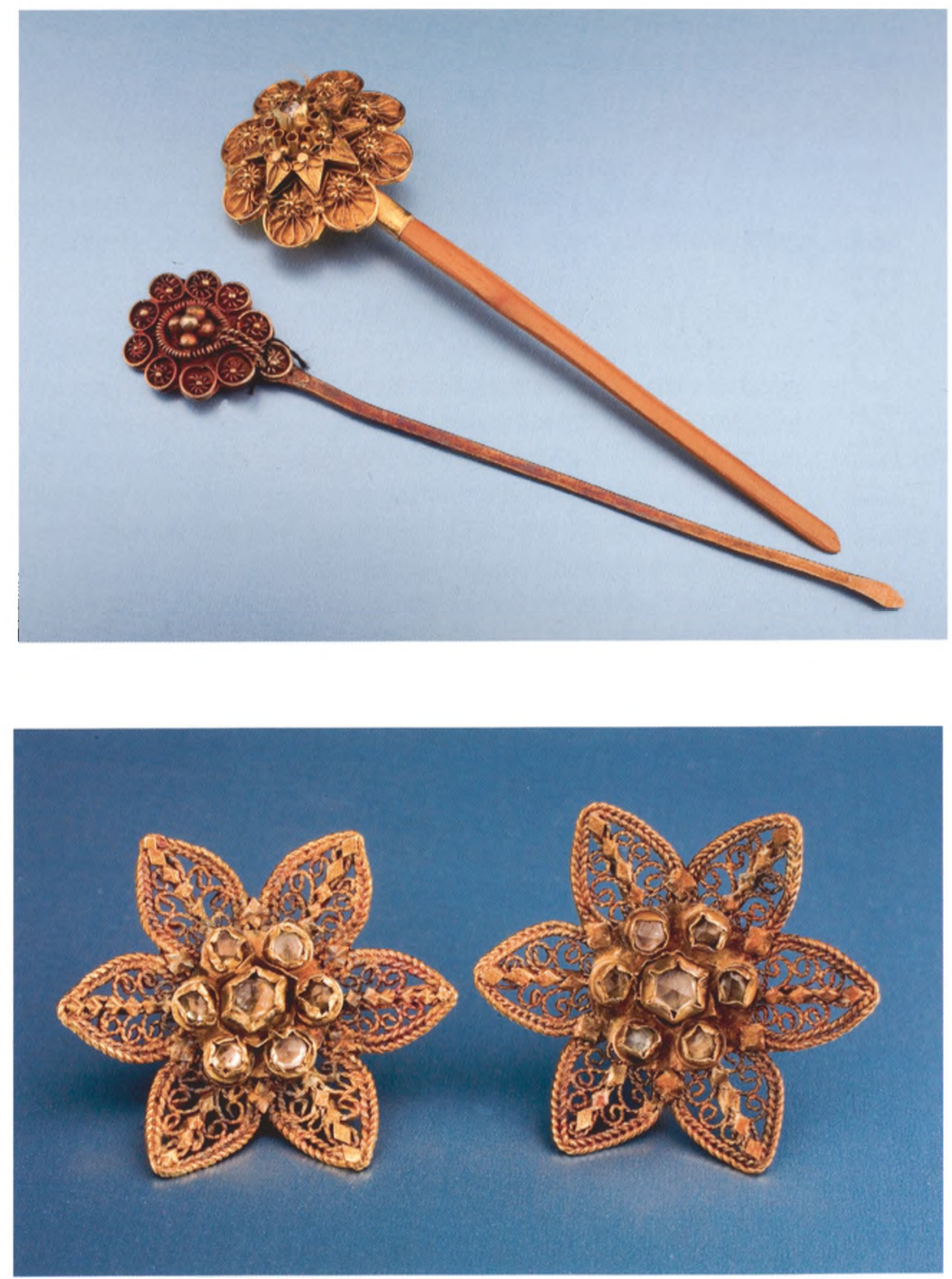

Museum (REM). ${ }^{4}$ Hoewel etnografisch zeer interessant en ook esthetisch van groot belang is over deze collectie tot op heden nauwelijks gepubliceerd. Reden te meer om in dit tentoonstellingsbericht aandacht te besteden aan enkele van de prachtige Veltman-voorwerpen die in de Sumatra-tentoonstelling zijn opgenomen.

\section{Sieraden}

Het goud dat gebruikt werd voor de sieraden was vaak Chinees bladgoud uit Penang, vermengd met zilver verkregen uit omgesmolten zogenoemde pilaardollars (Spaanse dollars). ${ }^{5}$ Veel van de gouden sieraden die Veltman verzamelde, hebben een wat rode kleur. Een kleur die men kreeg door het gouden voorwerp uren te koken in een mengsel van water, citroenzuur, zout en zwavel. ${ }^{6}$ Een van de twee haarspeldepovanaabeeldingi 1 is gemaakt zaar dit: $36 \mathrm{PM}$ rode goud. De haarspelden hebben beide een bloemmotief. De kleinstę free access 
haarspeld heeft in het midden een knop in het zogenaamde viskuit-motief (boh eungkot): kleine op elkaar gestapelde balletjes. ${ }^{7}$

De gouden oorsieraden zijn vervaardigd in ajourtechniek (afb. 2). In het midden zes steentjes om een grotere steen gegroepeerd. In plaats van het viskuitmotief zijn de bladeren versierd met raseule, een ruitmotief. De oorsieraden zijn bestemd om bevestigd te worden op oorschijven van hoorn of hout.

\section{Gordel}

In afbeelding 3 is een gordel te zien die geheel met kralenwerk is bedekt. De kleurrijke vogels en bloemen steken prachtig af tegen de blauwe achtergrond. De gordel is aan de binnenkant gevoerd met gele zijde.

De rechthoekige gordelplaat met geschulpte randen is van zilver, bedekt met een gouden plaat met versieringen van concentrische rijen bloemen, bladeren en vogels. Deze gordel is van Chinese makelij.

\section{Broek}

Veltman verzamelde veel textiel: prachtige doeken, en ook kleding. Deze broek, gedragen door vrouwen, is gemaakt van zijde. Het model, wijd van boven met smaller wordende pijpen, is zo gemaakt dat het eenieder past. Het kruis en de binnenkant van de broekspijpen zijn rijkelijk versierd met waterleliemotieven in gouddraad (afb. 4).

\section{Kris met schede, naar Buginees model}

De Javaanse kris is sinds de $13^{e}$ eeuw op Sumatra gebruikt, vermoedelijk geïntroduceerd door de legers van koning Kertanegara van Singhasari. Ook de Buginezen uit Zuid-Sulawesi, die handel dreven over de hele archipel brachten hun eigen type kris mee. Dit type was van oorsprong ook naar Javaans handwerk gemaakt, maar de Buginezen gebruikten nikkel bevattend metaal van eigen bodem. Met name de grepen van de Sumatraanse krissen zijn beïnvloed door de Buginezen. ${ }^{8}$
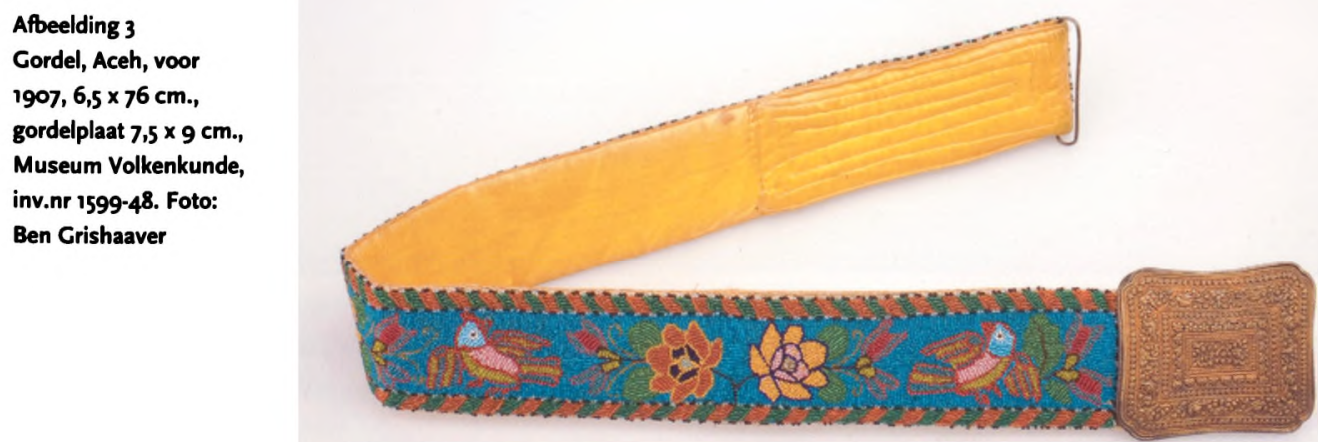


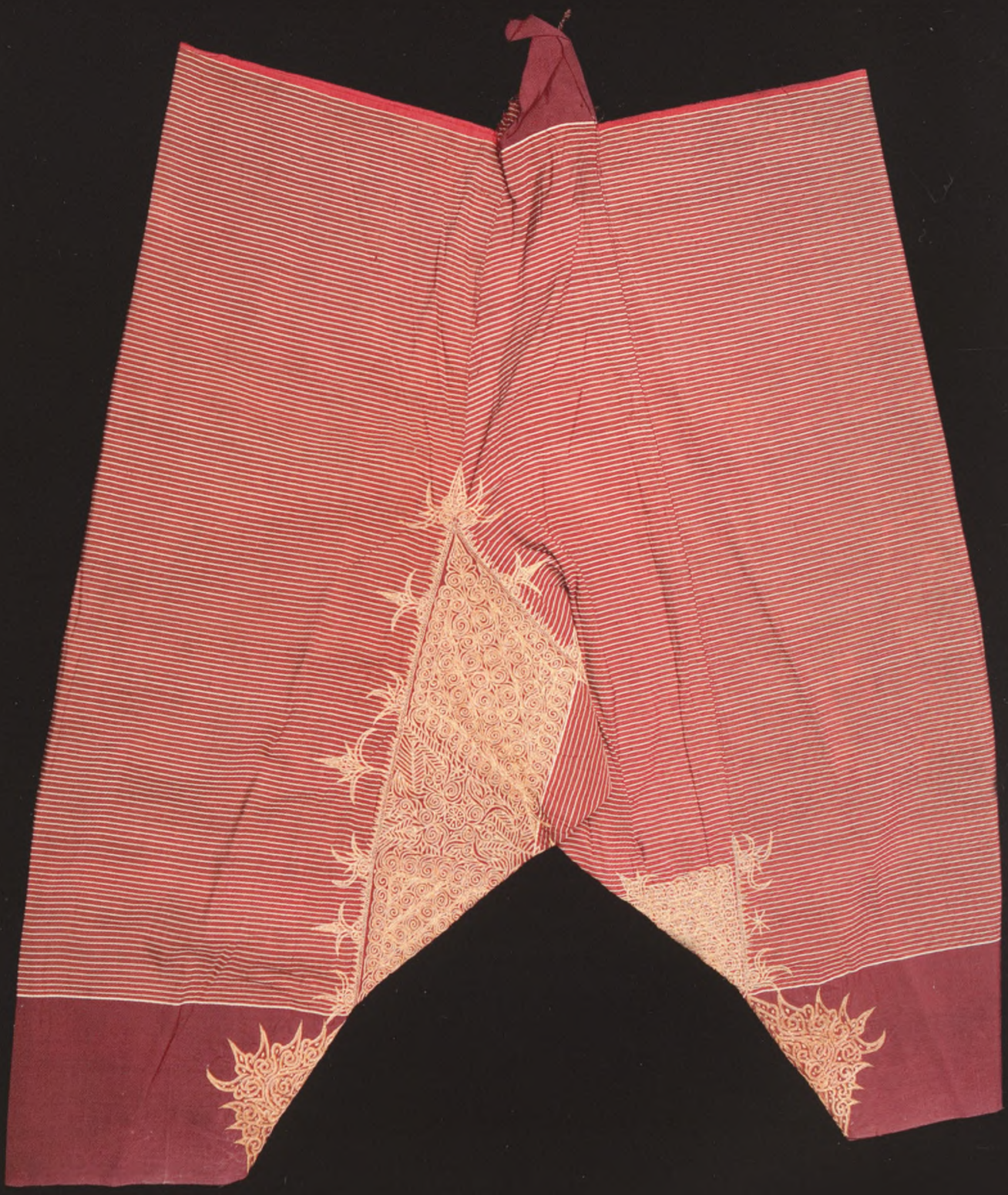

Afbeelding 4 (links)

Broek, Aceh, voor 1907,

I. $88 \mathrm{~cm}$., b. $52 \mathrm{~cm}$.,

Museum Volkenkunde,

inv.nr 1599-261. Foto:

Downloaded from Brill.comø4/26/2023 02:15:36PM Ben Crishaaver 


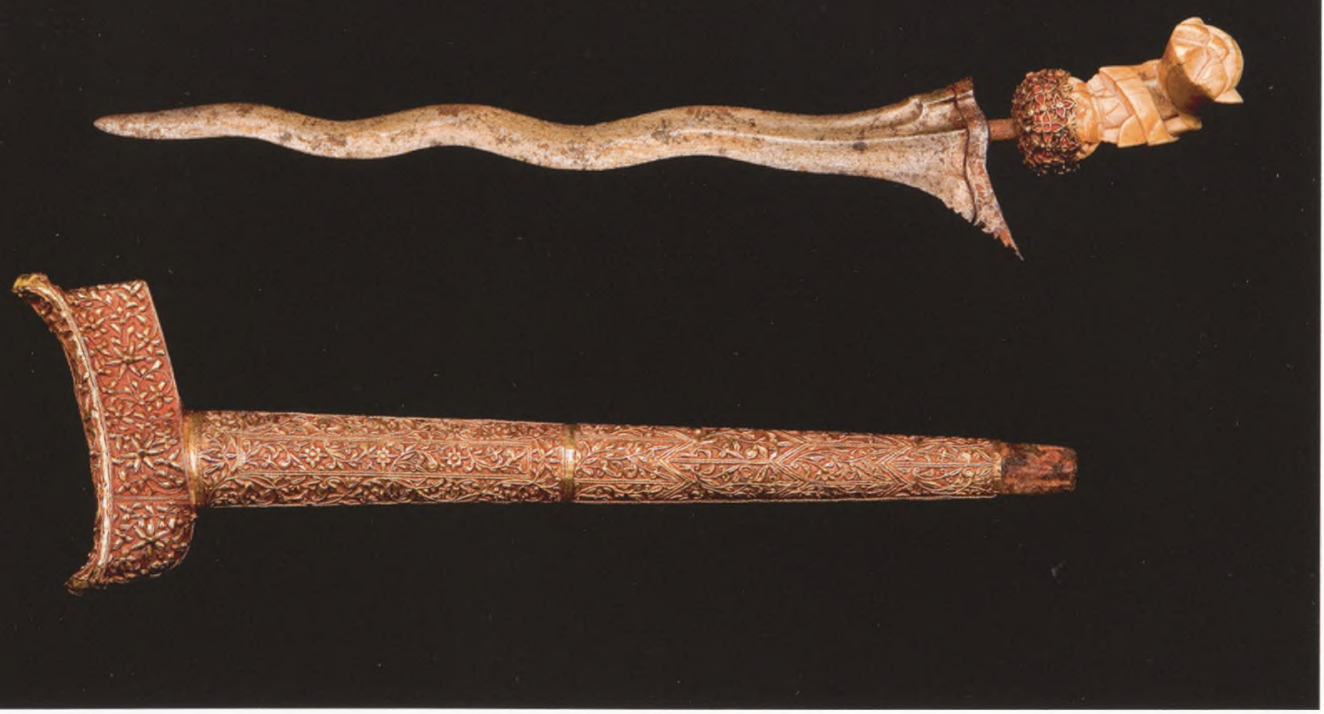

Afbeelding 5

Kris met schede, Aceh, voor $1907,43 \times 11,5 \mathrm{~cm}$., Museum Volkenkunde, inv.nr 1599-660. Foto: Ben Grishaaver
De naam van deze door Veltman verzamelde kris, kréh boegéh, geeft al aan dat deze naar een Buginees model is gemaakt (afb. 5). De kris heeft een vlammend lemmet met zeven bochten. De greep, gemaakt van been, is een gestileerde vogelfiguur. De steelring is van goud, versierd met rode edelstenen. Hij is van Acehse makelij. De schede, schoen en het mondstuk zijn van hout en helemaal overtrokken met goud. De kris behoorde aan Teuku Umar, een belangrijke Acehse leider die streed tegen de Nederlanders.

\section{Potloodtekening, ingekleurd met waterverf, van een mythische dier ('boeraq')}

De boeraq is het mythische dier dat de Profeet Mohammed naar de hemel vervoerde. Het dier wordt vaak afgebeeld met een gezicht van een mens. Hier heeft hij een gezicht van een man (afb. 6). Aan zijn voorbenen heeft hij klauwen; zijn achterbenen zijn menselijk. Een dunne staart hangt naar beneden, een grote staart van veren wijst omhoog. Op zijn rug, boven zijn vleugels, heeft hij een draagstoel met wapens, wat naar koninklijk erfgoed zou kunnen verwijzen. ${ }^{9}$

Boven hem vliegen twee paradijsvogels. Onder hem is een jachttafereel te zien: een man schiet op een tijger. Links helpt een man een kleine jongen in de boom te klimmen terwijl een andere man met zijn speer in de staart van een slang steekt. De slang bijt in de poot van een klein blauw dier. ${ }^{10}$ De tekening is één van de 13 werken die verzameld werden door Veltman. Alle tekeningen in zijn collectie zijn gemaakt door Teungkoe Teungoh, een autonoom hoofd (Olëèbalang) van Pate, een subdistrict van Poelo Raya.

Het bijzondere aan deze tekeningen is datwzetonen hoerde islam/is/2023 02:15:36 PM eigengemaakt en niet is opgedrongen. Het islamitisch verbod op het ${ }^{\text {via free access }}$ 


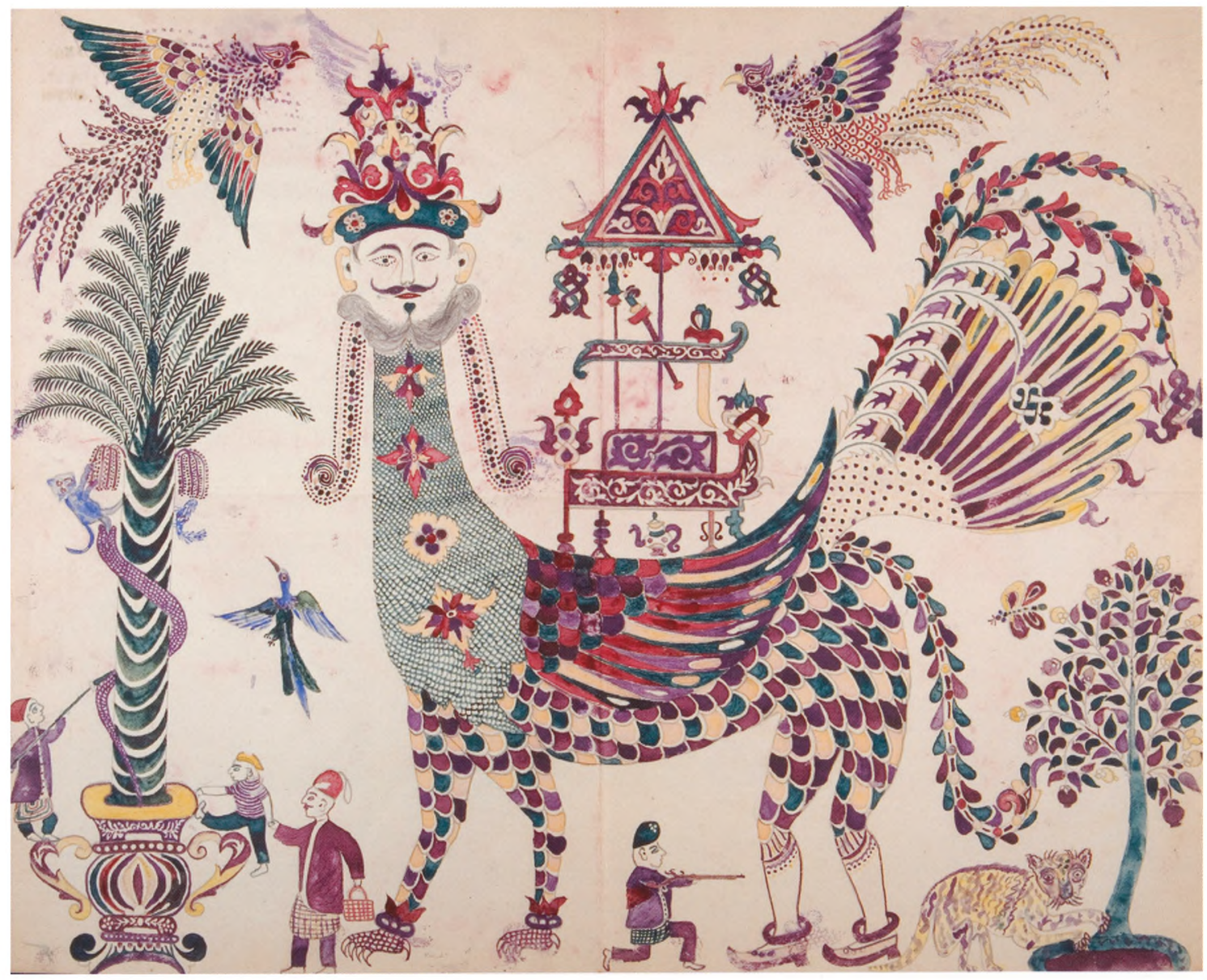

Afbeelding 6

Aquarel van een boeraq, Aceh, voor 1907, $42 \times 34$ cm., Museum Volkenkunde, inv.nr 1599-671. Foto: Ben Grishaaver afbeelden van levende wezens, heeft de creativiteit van de kunstenaars alles behalve beperkt. ${ }^{11}$

De tekening van de mythische vogel is ook gebruikt als voorkant voor het boek Sumatra; Crossroads of Culture, dat verschijnt bij de tentoonstelling. Het boek geeft een bredere kijk op de rijke erfenis die het eiland heeft gekregen door haar strategische ligging aan de eeuwenoude handelsroutes.

Bezoekers van de Sumatra-tentoonstelling in Museum Volkenkunde worden aan de hand van vijf thema's door belangrijke invloedsferen geleid: het hindoe-boeddhisme, de islam, Chinese, Indonesische en Europese invloeden. In het kader van het samenwerkingsproject met het Museum Nasional in Jakarta was de tentoonstelling tot begin september al met groot succes te zien in de Indonesische hoofdstad. Gelukkig kunt u deze bijzondere tentoonstelling vanaf volgende maand ook dichter bij huis bezoeken.

- Sumatra tercinta. Het geliefde eiland.

Van 14 oktober $2009 \mathrm{t} / \mathrm{m} 25$ april 2010

Museum Volkenkunde

Steenstraat $1-2312$ BS Leiden

di - zo van 10.00 tot 17.00 uur

www.museumvolkenkunde.nl 
1. Met veel dank aan Fransje Brinkgreve voor het informatiemateriaal.

2. P. ter Keurs, 'Collectieprofiel Insulair Zuidoost-Azië', in: De mens in beeld,

Verzamelde collectieprofielen Museum Volkenkunde, Leiden, 2008, p. 10.

3. T.J. Veltman, 'Nota betreffende de Atjèsche goud- en zilversmeedkunst', Tijdschrift van het Bataviaasch Genootschap 47: 341-380.

4. H.W. Fischer, Gids voor de Tentoonstelling van ethnographische voorwerpen uit Atjeh bijeengebracht door Th.J. Veltman, Leiden, 1907, p. II (inleiding).

5. Veltman, Op.cit. (noot 3), p. 345.

6. Veltman, Op.cit. (noot 3), p. 347.

7. Veltman, Op.cit. (noot 3), p. 352.

8. David van Duuren, De kris, Amsterdam, 1996, pp. 88-90.

9. D.R. Widyastuti, 'Islam in Sumatra: history and culture', in: F. Brinkgreve en R. Sulistianingsih (red), Sumatra; crossroads of cultures, Leiden, te verschijnen in oktober 2009.

10. S. Lauren, Drawings from the Veltman collection, 2008, pp. 18-21 [manuscript]. 11. Widyastuti, Op.cit. (noot 9).

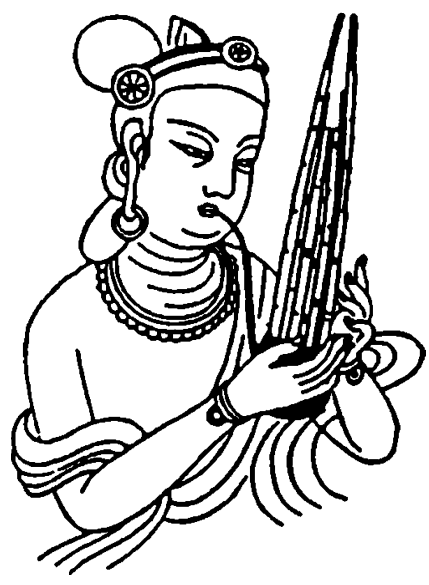

HET

TRAGE

VUUR

\section{Tijdschrift}

voor

Chinese literatuur

www.tragevuur.com

infolatragevuur.com

$t / f:$ (NL) 071-5724264
- Verschaft Nederlandse en Vlaamse lezers in hun eigentaal toegang tot de Chinese literatuur.

- Biedt een uitgebreide keuze: van klassieke poëzie tot hedendaags proza. Essays, interviews en boekbesprekingen plaatsen de auteurs en hun werk in de context van de Chinese traditie en van de wereldliteratuur, en ter verluchtiging worden regelmatig kunstreproducties opgenomen.

Verschijnt vier keer per jaar (waaronder meerdere themanummers); losse nummers $€ 8,00$ / abonnementen $€ 25,00$.

Wie nu een abonnement neemt krijgt het boek Pa pa pa van Han Shaogong (Uitgeverij De Geus) cadeau. 